\title{
Epidermal Growth Factor Receptor Tyrosine Kinase Inhibition Up-regulates Interleukin-6 in Cancer Cells and Induces Subsequent Development of Interstitial Pneumonia
}

\author{
Yukari Ishiguro, ${ }^{1,3, *}$, Hitoshi Ishiguro ${ }^{2,3, *}$, and Hiroshi Miyamoto ${ }^{3}$ \\ ${ }^{1}$ Department of Biology and Function in the Head and Neck, Yokohama City University Graduate School of Medicine, \\ Yokohama, Kanagawa, Japan \\ 2 Department of Urology, Yokohama City University Graduate School of Medicine, Yokohama, Kanagawa, Japan \\ ${ }^{3}$ Department of Pathology and Laboratory Medicine, University of Rochester Medical Center, Rochester, New York \\ ${ }^{*}$ Y. I. and H. I. contributed equally to this work.
}

Correspondence to: Yukari Ishiguro, email: yukariishiguro@gmail.com

Keywords: fibrosis, EGFR-TKI, IL-6, cytokine, side-effect

Received: March 15, $2013 \quad$ Accepted: March 29, $2013 \quad$ Published: March 31, 2013

This is an open-access article distributed under the terms of the Creative Commons Attribution License, which permits unrestricted use, distribution, and reproduction in any medium, provided the original author and source are credited.

\section{ABSTRACT:}

Acute interstitial pneumonia is one of serious side effects of epidermal growth factor receptor (EGFR)-tyrosine kinase inhibitor (TKI) treatment, while it often has significant clinical benefit in cancer patients. Therefore, it is necessary to clarify underlying mechanisms for the development of the adverse effects by EGFR-TKI. In the present study, we attempted to determine how EGFR-TKI treatment in cancer cells induced interstitial pneumonia. The growth of tongue cancer HSC-3 and lung cancer A549 cell lines treated with EGFR-TKI was assessed by MTT assay. Cytokines and growth factors in conditioned medium obtained from EGFR-TKI-treated cancer cells were analyzed using cytokine membrane array and ELISA. Interleukin-6 (IL6) promoter activity was measured by luciferase assay. We found that EGFR-TKI treatment significantly decreased the cell viability yet increased expression levels of IL-6 protein and mRNA, IL-6 secretion, and IL- 6 transcriptional activity in these lines. In addition, using the co-culture model and IL-6 treatment was found to increase the expression of collagen and a-actin, which were markers for fibrosis, in lung fibroblast cells. These results suggest that up-regulated IL-6 plays an important role in the development of EGFR-TKI-induced interstitial fibroblastic proliferation. Therefore, blocking of IL-6 signaling could be beneficial to cancer patients undergoing EGFR-TKI treatment for reducing the risk of its unfavorable effects.

\section{INTRODUCTION}

Epidermal growth factor (EGF) is a well-known growth factor that promotes cancer progression. EGF stimulates cancer growth through the EGFR receptor (EGFR) pathway. Most of cancer tissues are shown to overexpress EGFR, and EGF-EGFR axis has been considered a attractive target for cancer treatment. Indeed, EGFR-tyrosine kinase inhibitors (EGFR-TKIs) have been developed and clinically used in patients with malignancy, especially non-small cell lung carcinoma $[1,2]$. EGFR-TKI effectively blocks the EGFR pathway via suppression of EGFR phosphorylation and can therefore inhibit the growth of cancer cells dramatically. On the other hand, the effect of EGFR-TKI is dependent on mutations of EGFR and KRAS, MET amplification, and the interaction between EGFR and HER-2 and so on [26]. More importantly, EGFR-TKI treatment gives rise to severe side effects, including acute interstitial pneumonia [7]. Although some studies have suggested risk factors for side effects [8-12], detailed molecular mechanism for their development remains unknown.

Recently, Kim et al. indicated that EGFR-TKI activated STAT3 in non-small cell lung cancer cells [13]. They also showed that STAT3 activation was caused by interleukin-6 (IL-6) in an autocrine manner. IL-6 is one 
of inflammatory cytokines and is well known as a cancer progression-related cytokine $[14,15]$. Because STAT3 is one of the targets for anti-cancer drug resistance [16], most of investigations have been only focused on how IL-6 regulates the drug resistance in EGFR-TKI-treated cancer cells.

In the current study, we explored therapeutic effects of EGFR tyrosine kinase inhibition, using two EGFRTKIs and an $\alpha$ EGFR antibody, in human tongue and lung cancer cell lines. Further, we found that EGFR blocking could increase IL-6 in the cancer cells. Because IL-6 has been suggested to contribute to the development or progression of acute interstitial pneumonia [17-20], we anticipated the possible linkage between IL-6 from cancer cells and EGFR-TKI-induced acute interstitial pneumonia. Our results suggested that IL-6 secreted from EGFR-TKItreated cancer cells induced lung fibrosis. Accordingly, a combination of IL-6 pathway blocker and EGFR-TKI may show more favorable effects in cancer patients.

\section{RESULTS}

\section{EGFR-TKI inhibits the growth of cancer cell lines.}

We first investigated the growth inhibition effect of EGFR-TKI treatment in human tongue and lung cancer cells, using MTT assay. AG1478 treatment could decrease

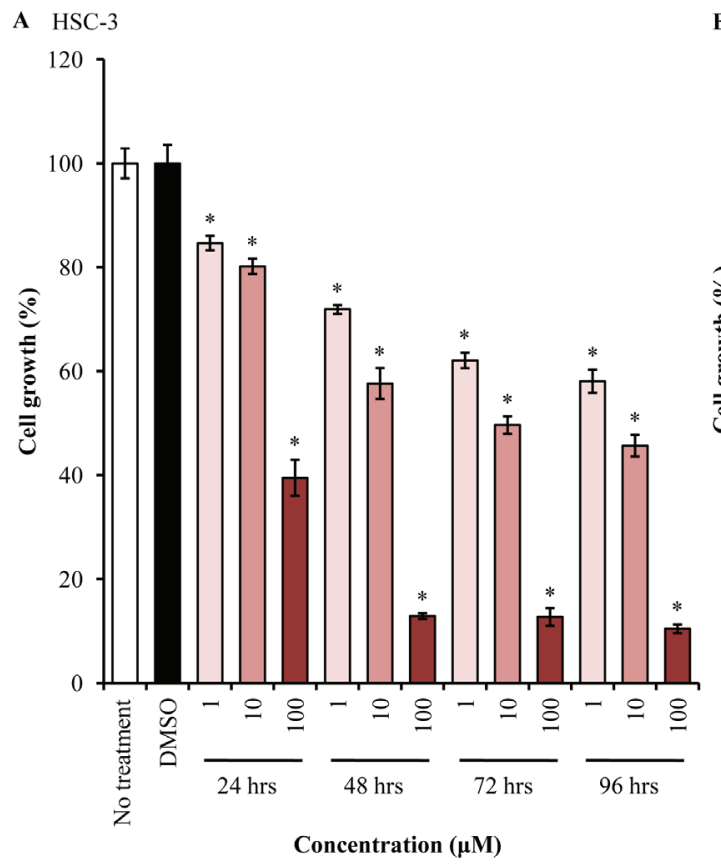

the growth of HSC-3 cells dramatically in dose- and timedependent manners, as compared with mock-treated cells (Figure 1A). The growth of A549 cells was similarly inhibited by AG1478 (Figure 1B).

To confirm the inhibition of EGF pathway by EGFR-TKI treatment, HSC-3 and A549 cells were treated with EGF after the pre-treatment of AG1478 and $\alpha$ EGFR antibody. EGF treatment stimulated EGFR phosphorylation at $10 \mathrm{~min}$ (Figure 2). EGF treatment also increased phosphorylation of STAT3 and MAPK in HSC-3 cells as well as Akt phosphorylation in A549 cells. When cells were pre-treated with AG1478 or $\alpha$ EGFR antibody, EGFR phosphorylation was inhibited especially in HSC3. AG1478 also inhibited phosphorylation of STAT3, Akt, and MAPK. These results suggest that EGFR-TKI and $\alpha$ EGFR antibody decrease cell growth via inhibiting EGF phosphorylation.

\section{Cancer cells treated with EGFR-TKI secretes IL-6}

Western blotting was then performed in HSC-3 cells treated with AG1478 for up to $24 \mathrm{hrs}$. As shown in Figure 3A, EGF induced EGFR and STAT3 phosphorylation from $10 \mathrm{~min}$ to $6 \mathrm{hrs}$. Further, AG1478 pre-treatment effectively prevented their phosphorylation induced by EGF stimulation. On the other hand, AG1478 pretreatment increased STAT3 phosphorylation at $24 \mathrm{hrs}$ while EGF treatment did not induce the phosphorylation of EGFR and STAT3 at $24 \mathrm{hrs}$. We also confirmed STAT3

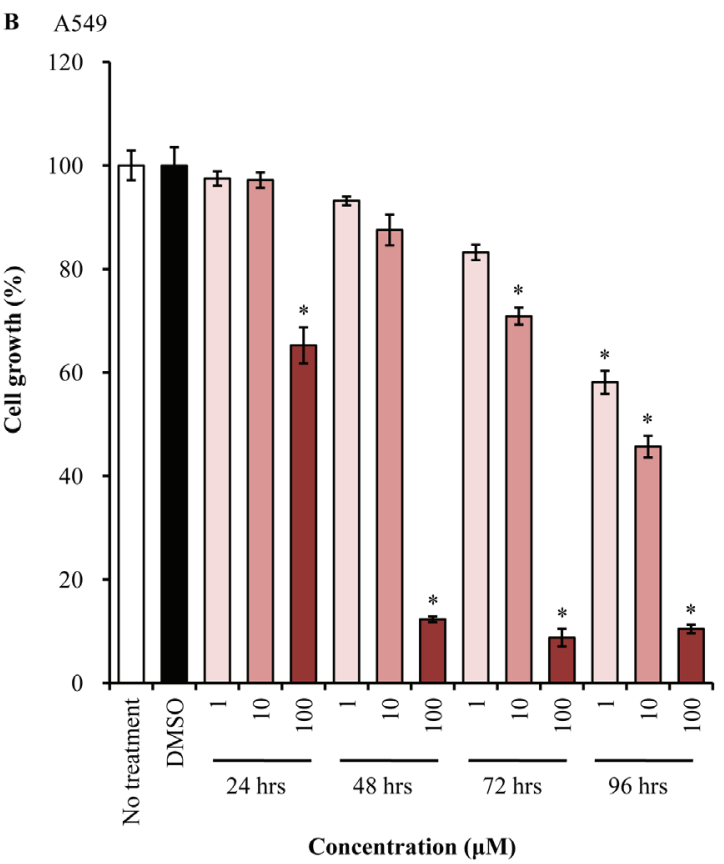

Figure 1: EGFR-TKI inhibits cell proliferation. HSC-3 (A) and A549 (B) cells were treated with different concentrations (1-100 $\mu \mathrm{M})$ of AG1478 for different durations (24-96 hrs). Then, cell proliferation was measured $(n=6)$, using a kit and absorbance at $530 \mathrm{~nm}$ or $630 \mathrm{~nm}$. Bars represent average \pm standard deviation (SD) of three independent experiments. $* \mathrm{P}<0.001$ by student's $t$ test ( $v s$ DMSOtreated cells). 
phosphorylation at $24 \mathrm{hrs}$ using another EGFR-TKI, ZD1839 (Figure 3B).

Growth factors or cytokines are well known to increase STAT3 phosphorylation [21]. Therefore, we anticipated that growth factors or cytokines could be induced by EGFR-TKI treatment. Using cytokine membrane arrays, we screened factors that were up- or down-regulated in Conditioned Medium (CM) obtained from EGFR-TKI- or $\alpha$ EGFR antibody-treated cancer cells. Of the factors, IL-6 was found to be augmented significantly in CM with EGFR-TKI and $\alpha$ EGFR antibody, compared with control CM. (Figure 4A and B). In addition, we examined IL-6 protein secretion by ELISA and mRNA expression by qPCR in HSC-3 cells. All of EGFR blocking reagents increased IL-6 secretion (Figure 4C). Similarly, these EGFR blocking reagents also increased $I L-6$ mRNA in HSC-3 cells, compared with that in control- or DMSO-treated cells (Figure 4D). These results suggested increases in $I L-6$ mRNA levels were regulated at a transcriptional level. Then, we tested the effects of EGFR blocking on IL-6 promoter transcriptional activity in HSC-3 cells, using luciferase reporter gene assay. Because the IL-6 promoter contains AP-1 binding site, AP-1 transcription was also assessed. As expected, ZD1839 treatment induced transcriptional activity of IL-6 and AP-1 (Figure 4E). Thus, EGFR blocking reagents appeared to activate IL- 6 promoter transcription presumably via the regulation of AP-1 activation.

\section{IL-6 increases COL1A1 expression in lung fibroblasts.}

Because IL-6 has been linked to the development of acute interstitial pneumonia [15-18], we expected that EGFR-TKI treatment-induced IL-6 production in cancer cells resulted in lung fibrosis. To confirm this hypothesis, we assessed the expression of fibrosis markers in normal lung cells, COL1A1 and $\alpha$-actin, in lung fibroblastic cells. CM obtained from HSC-3 cells treated with EGFR-TKI or $\alpha$ EGFR antibody was added to OUS-11 cell culture. The levels of COL1A1 mRNA in OUS-11 cells were higher when treated with AG1478 or $\alpha$ EGFR antibody (Figure 5A). We also assessed COL1A1 and $\alpha$-actin protein expression using the co-culture models (HSC-3/OUS11, HSC-3/HEF1) followed by western blot. In both cell lines AG1478 or $\alpha$ EGFR antibody increased the levels of COL1A1 and $\alpha$-actin proteins (Figure 5B). To confirm that IL-6 itself up-regulates COL1A1 and $\alpha$-actin, we examined whether recombinant IL-6 increased COL1A1

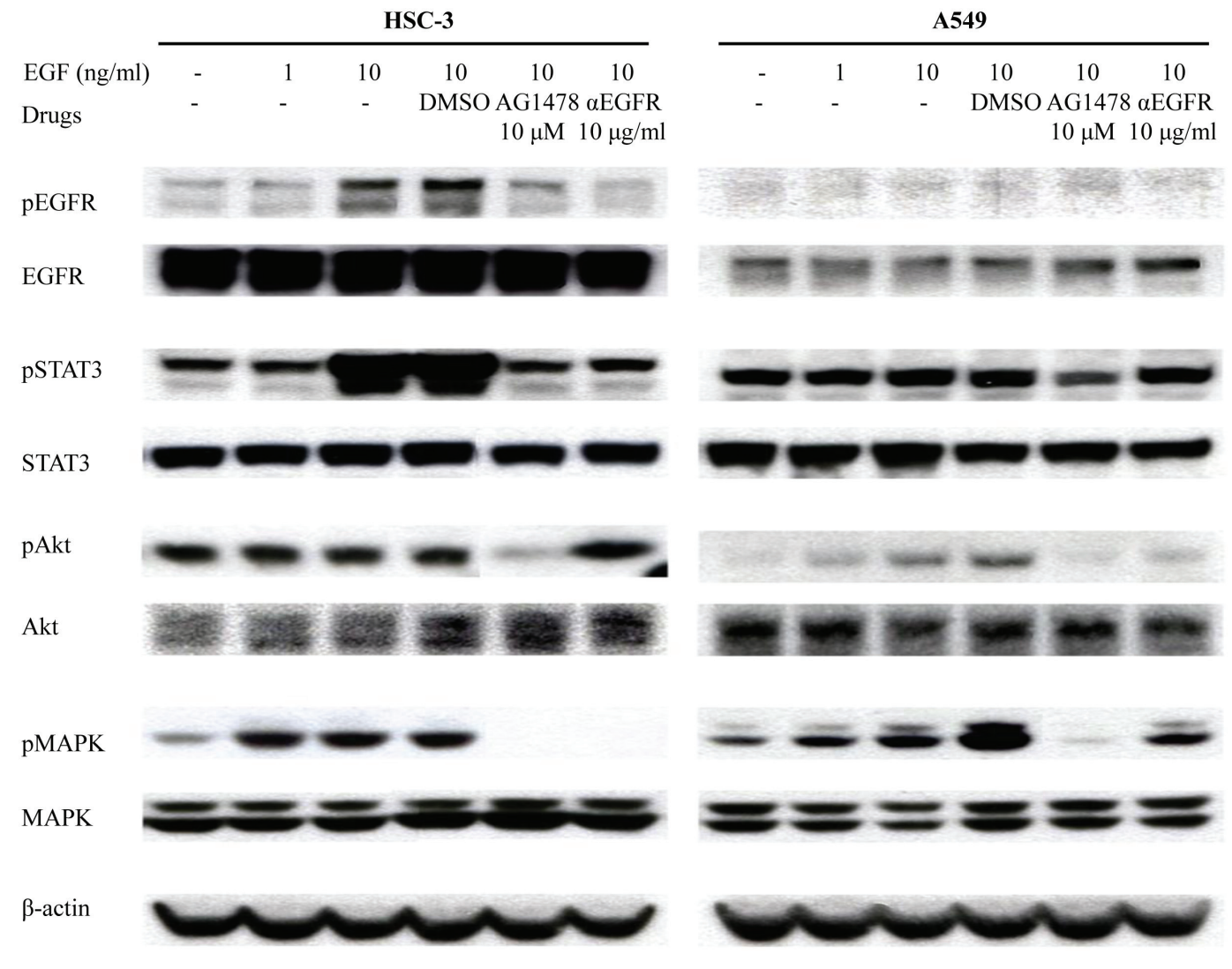

Figure 2: EGFR-TKI inhibits phosphorylation of molecules related to downstream signaling of EGFR. HSC-3 and A549 cells treated with EGF and other drugs as indicated were analyzed on western blotting, using antibodies to the downstream signaling of EGFR, including pEGFR (175 kDa), EGFR (175 kDa), pSTAT3 (86 kDa), STAT3 (86 kDa), pAKT (60 kDa), AKT (60 kDa), pMAPK (42 and $44 \mathrm{kDa}$ ), and MAPK (42 and $44 \mathrm{kDa}) . \beta$-Actin (43 kDa) served as an internal control. 
expression. When OUS-11 and HFL1 cells were treated with IL-6, the expression of COL1A1 protein (Figure 5C) and COL1A1 mRNA (Figure 5D) was significantly enhanced. In addition, $\alpha$ IL- 6 antibody pre-treatment antagonized COL1A1 mRNA expression in IL-6-treated OUS-11 cells (Figure 5D). Other Collagen 1A subtypes (COL1A2 and COL1A3) were also up-regulated by IL-6 treatment, which was inhibited by $\alpha$ IL- 6 antibody. These results suggest that IL-6 may play a key role in the development of EGFR-TKI-induced lung fibrosis.

\section{DISCUSSION}

It has been shown that EGF promotes cancer cell proliferation, migration, and invasion. Therefore, EGFR is one of the molecular targets for the treatment of malignancies, such as non-small cell lung cancer. In this study, we confirmed that EGFR-TKI had antitumor effects in not only lung adenocarcinoma but also tongue squamous cell carcinoma. Interestingly, growth suppression was more significant in HSC-3 tongue cancer cells than in A549 lung cancer cells. Thus, EGFR-TKI might also be effective in patients with tongue cancer.

EGFR-TKI has been clinically used in cancer patients although it is occasionally associated with severe side effects, including acute interstitial pneumonia. Therefore, to use EGFR-TKI more safely, it is necessary to clarify the mechanism of acute interstitial pneumonia development induced by EGFR-TKI. We found that
EGFR-TKI treatment in cancer cells increased IL-6 secretion, even if EGFR phosphorylation was completely blocked by EGFR-TKI. Furthermore, EGFR blocking, using an $\alpha$ EGFR antibody that neutralizes EGFR by competition with EGF on the external domain of EGFR, also resulted in increases in IL-6 production from cancer cells. Therefore, IL-6 production by EGFR blocking might be rather the general reaction by EGFR blocking than EGFR-TKI-specific reaction.

Consistent with previous findings [13], we showed the enhancement of $I L-6$ mRNA in EFGR-TKI-treated cancer cells. Thus, IL-6 expression might be controlled at a transcriptional level. Moreover, we showed EGFRTKI treatment activated IL-6 promoter in HSC-3 cells. For IL-6 mRNA transcription, some transcriptional factors, such as NFאB or AP-1, are needed to be activated [22]. Takada et al. showed Fra-1 was involved in lung interstitial disease associated with EGFR-TKI treatment in lung cells [23]. Indeed, AP-1 was activated by EGFRTKI in our reporter assays. Thus, AP-1 activation might be one of the mechanisms for IL-6 overexpression in cancer cells. Other possibilities include activated STAT3 induced IL-6 transcription through IL-6-STAT3 axis as a positive feedback loop [24]. Yao et al. indicated that TGF $\beta$ could increase IL-6 at a transcriptional level independent of EGFR activation [25], which may explain a mechanism for up-regulation of IL-6 promoter transcriptional activity by EGFR-TKI. Further investigations are needed to clarify how EGFR-TKI regulates IL-6 production in cancer cells.

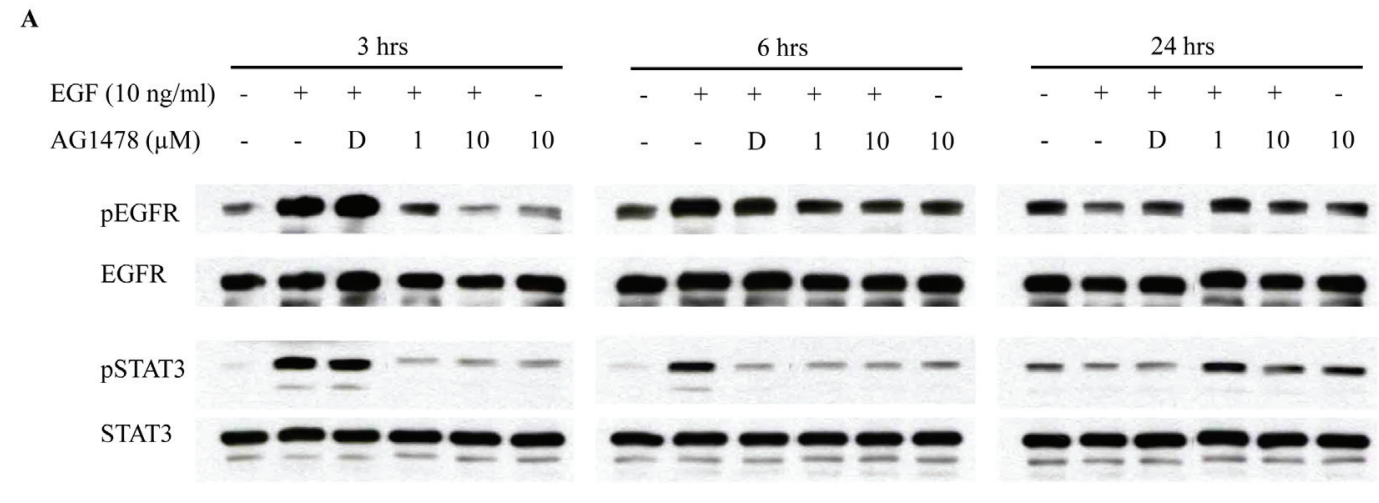

B

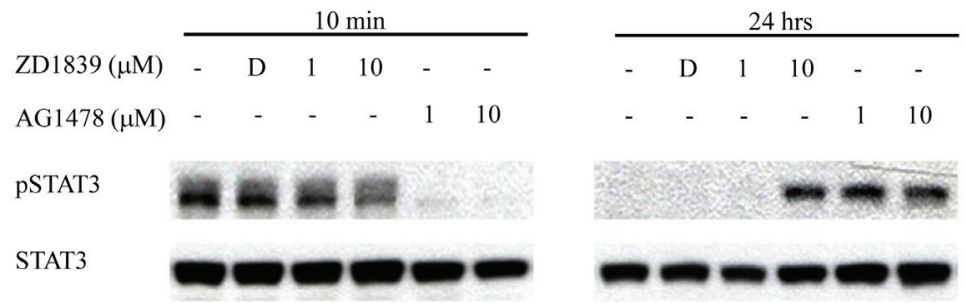

Figure 3: EGFR-TKI increases phosphorylation of STAT3. (A) HSC-3 cells treated with EGF and/or AG1478 for up to 24 hrs were analyzed on western blotting, using antibodies to pEGFR (175 kDa), EGFR (175 kDa), pSTAT3 (86 kDa), and STAT3 (86 kDa). (B) HSC-3 cells treated with AG1478 or ZD1478 for 10 min or 24 hrs were analyzed on western blotting, using antibodies to pEGFR (175 kDa), EGFR (175 kDa), pSTAT3 (86 kDa), and STAT3 (86 kDa). D, DMSO. 
A
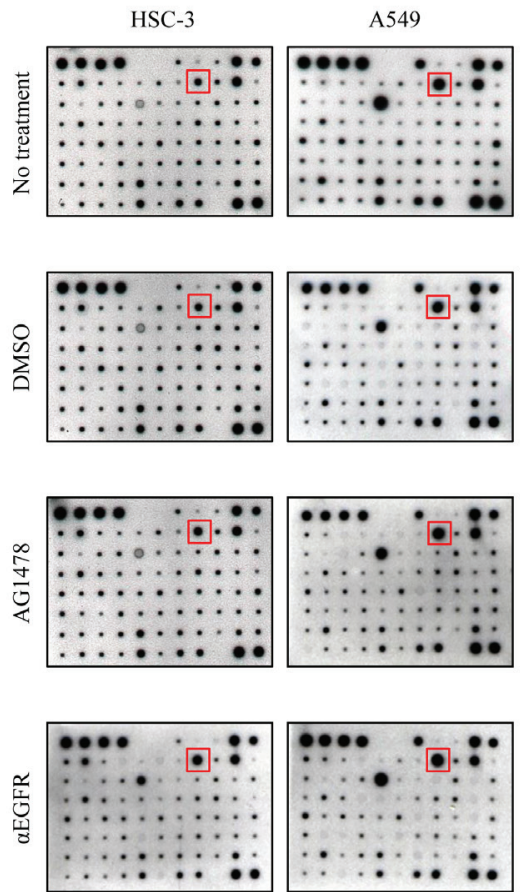

B
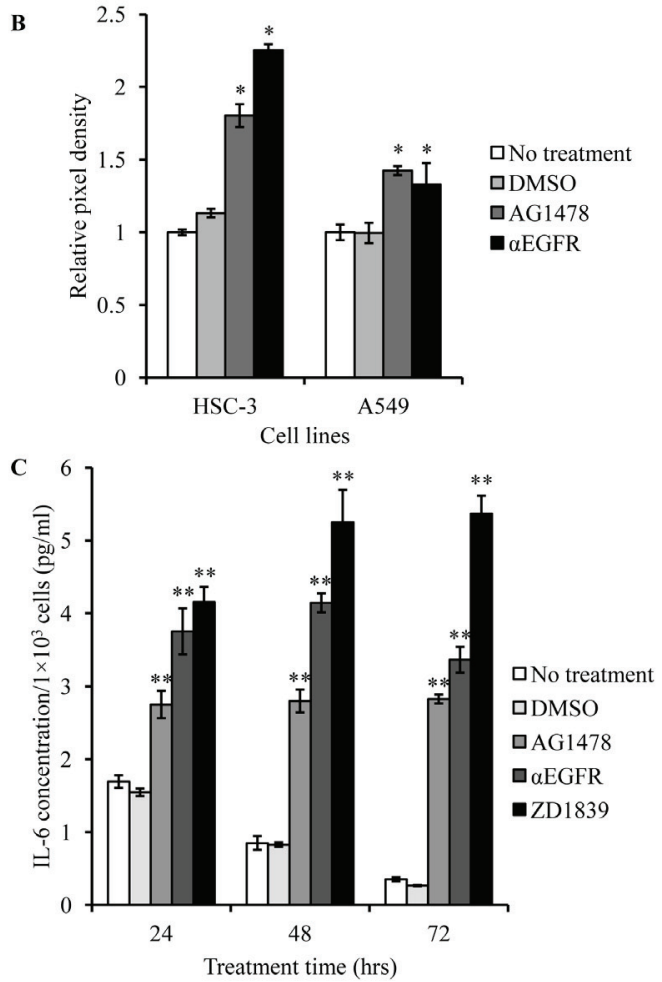
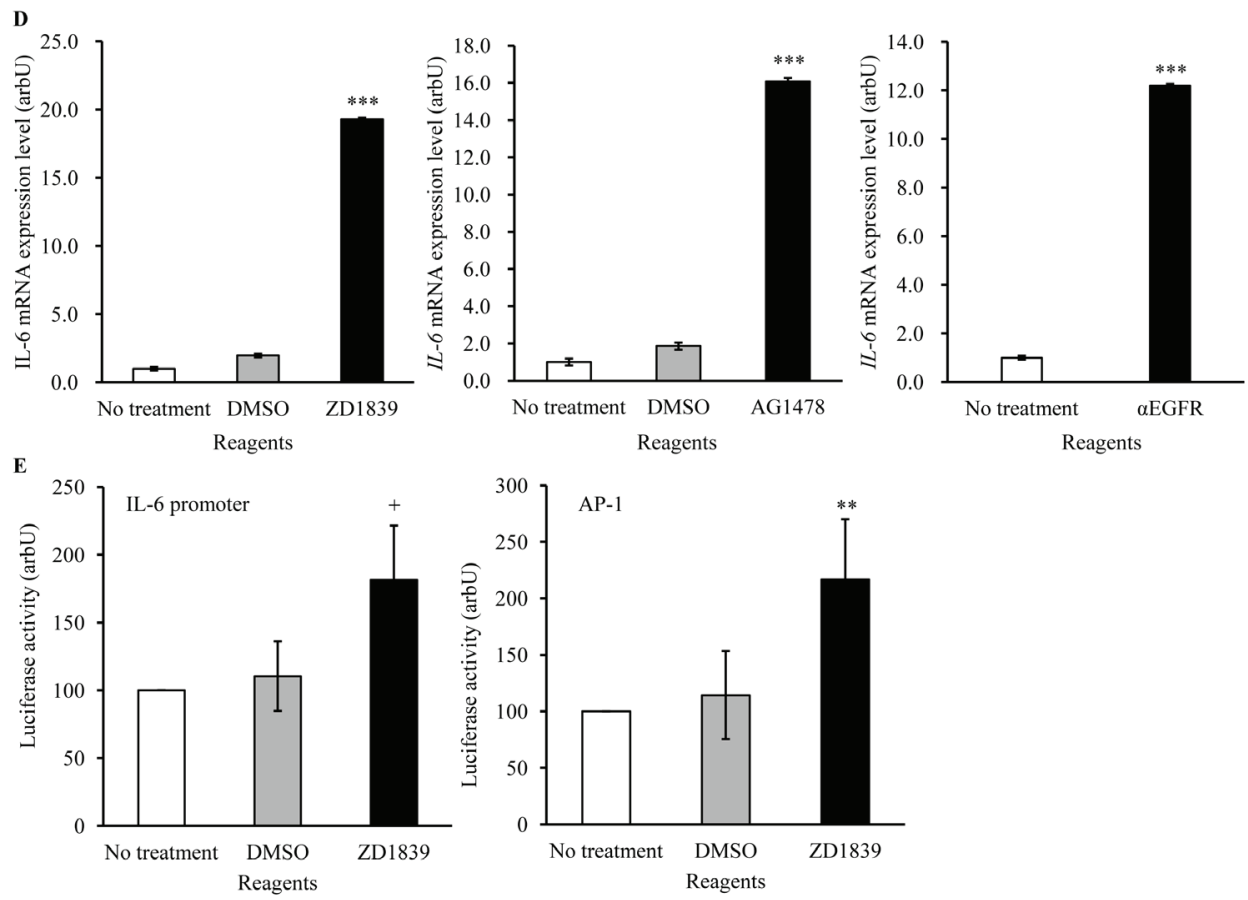

Figure 4: IL-6 is increased in cancer cells treated with EGFR-TKI. (A) HSC-3 and A549 cells were treated with AG1478 (10 $\mu \mathrm{M})$ or $\alpha$ EGFR antibody $(10 \mu \mathrm{g} / \mathrm{ml})$ for $24 \mathrm{hrs}$. Then, cytokines and growth factors included in CM were assayed using cytokine membrane array. DMSO was used as a vehicle. (B) Detected signal density obtained from the results of cytokine membrane array was measured using ScionImage software. Positive control spots were used as the internal control. ${ }^{*} \mathrm{P}<0.01$ by student's $t$ test ( $v S$ DMSO). (C) HSC-3 cells were treated with AG1478 $(10 \mu \mathrm{M}), \alpha$ EGFR antibody $(5 \mu \mathrm{g} / \mathrm{ml}), \mathrm{ZD} 1839(10 \mu \mathrm{M})$ or DMSO for $24 \mathrm{hrs}$, and CM was collected and assayed using an IL-6 ELISA kit. **P $<0.001$ by student's $t$ test (vs DMSO). (D) HSC-3 cells were treated with AG1478 $(10 \mu \mathrm{M})$, ZD1839 $(10 \mu \mathrm{M})$, or $\alpha$ EGFR antibody $(5 \mu \mathrm{g} / \mathrm{ml})$. Then, IL-6 mRNA expression was measured using qPCR. GAPDH was used as the internal control. Bars represent average $\pm \mathrm{SD}$ of three independent experiments. $* * * \mathrm{P}<0.001$ by student's $t$ test ( $v S$ DMSO or no treatment). arbU; arbitrary units. (E) HSC-3 cells transfected with pGL4-IL-6 promoter luciferase vector or AP-1 luciferase vector were treated with DMSO or ZD1839 (10 $\mu \mathrm{M})$ for $48 \mathrm{hrs}$. Then, luciferase activity was assayed using the dual-luciferase reporter assay system. $+\mathrm{P}=0.01$ and $* * \mathrm{P}<0.01$ by student's $t$ test (vs DMSO). arbU; arbitrary units. 
From our findings, IL-6 from cancer cells could induce COL1A 1 and $\alpha$-actin expression in lung fibroblast cells, suggesting IL-6 was likely one of the important factors for lung fibrosis. Because IL-6 strongly induces the growth and invasion of cancer cells $[14,15]$, previous studies were focused on the relationship between IL-6 and anti-cancer treatment. On the other hand, IL-6 is also known to induce interstitial pneumonia [17-20]. Therefore, we focused on studying the role of IL-6 in the development of acute interstitial pneumonia induced by EGFR-TKI treatment. Other molecules, such as HSP70 [26] and TGF $\beta$ [27], have also been considered to involve interstitial pneumonia. Interestingly, these molecules are related to IL-6 expression $[25,28,29]$. Our results showed that $\alpha$ IL- 6 antibody blocked COL1A1 expression. Thus, IL-6 from cancer cells may play a central role in EGFR-TKI-induced interstitial pneumonia. Taken together, we propose the following mechanism for the development of interstitial pneumonia as an adverse effect of EGFR-TKI treatment (Figure 6). EGFR-TKI reduces EGFR phosphorylation, which results in decreases in phosphorylation of some other molecules under the EGFR pathway. Consequently, the growth of cancer cells is suppressed. On the other hand, EGFR-TKI activates AP-1 in cancer cells and produces a large amount of IL-6 while growth inhibition is observed. Increased IL-6 affects both cancer and lung fibroblast cells. In cancer cells, IL-6 induces chemoresistance through IL-6-STAT3 axis. In non-neoplastic cells, IL-6 induces fibrosis. Thus, IL-6 production from EGFR-TKI-treated cancer cells increases the risk of chemoresistance and acute interstitial pneumonia.

We demonstrate in vitro evidence suggesting that IL-6 from cancer cells induces acute interstitial pneumonia as one of mechanisms responsible for the occurrence of a side effect of EGFR-TKI treatment. Furthermore, our findings suggest that the inhibition of IL-6-STAT3 axis in patients treated with EGFR-TKI could be not only a therapeutic target for their cancers but also an option to prevent the development of acute interstitial pneumonia
A

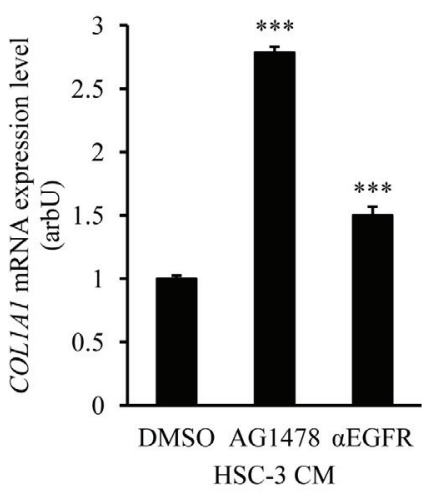

HSC-3 CM

C

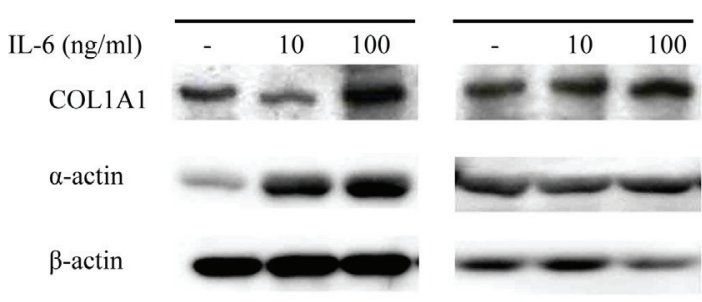

B

OUS-11

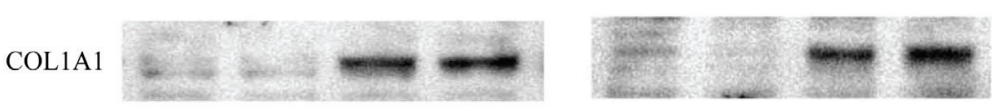

$\alpha$-actin

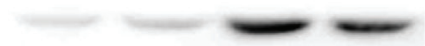

$\beta$-actin
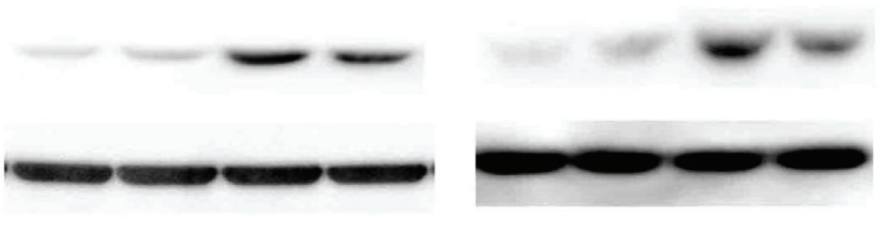

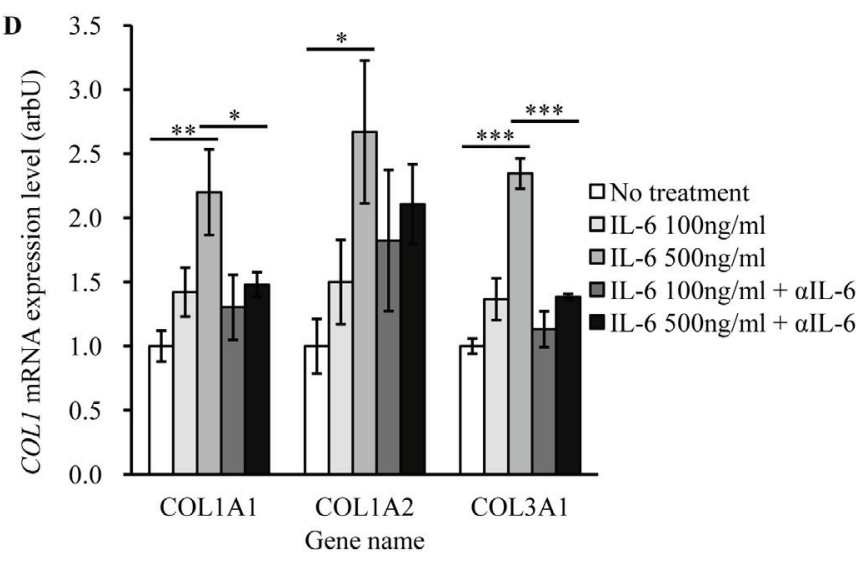

Figure 5: EGFR-TKI and IL-6 increase the expression of fibrosis markers. (A) OUS-3 cells were cultured with CM obtained from AG1478- or $\alpha$ EGFR antibody -treated HSC-3 cells for $72 \mathrm{hrs.} \mathrm{Then,} \mathrm{COL1A1} \mathrm{mRNA} \mathrm{expression} \mathrm{was} \mathrm{measured} \mathrm{using} \mathrm{qPCR.} \mathrm{GAPDH}$ was used as the internal control. Bars represent average $\pm \mathrm{SD}$ of three independent experiments. *** $\mathrm{P}<0.001$ by student's $t$ test $(v s$ DMSO). arbU; arbitrary units. (B) OUS-11 and HFL1 cells were co-cultured with AG1478- or $\alpha$ EGFR antibody -treated HSC-3 cells for 7 days. Then, COL1A1 $(210 \mathrm{kDa})$ and $\alpha$-actin $(42 \mathrm{kDa})$ proteins were assayed using western blotting. $\beta$-Actin was used as internal control. (C) OUS-11 and HFL1 cells treated with IL-6 were analyzed on western blotting, using antibodies to COL1A1 and $\alpha$-actin. $\beta$-Actin was used as internal control. (D) OUS-11 cells treated with IL-6 and/or $\alpha$ IL- 6 antibody for 72 hrs were assayed for qPCR to determine mRNA levels of COL1A1, COL1A2, and COL1A3. GAPDH was used as the internal control. Bars represent average \pm SD of three independent experiments. $* \mathrm{P}<0.01, * * \mathrm{P}<0.01$, and $* * * \mathrm{P}<0.001$ by student's $t$ test. arbU; arbitrary units. 
as an adverse effect. Thus, EGFR-TKI along with an IL-6 inhibitor might be more effective and safer treatment in patients with malignancy.

\section{METHODS}

\section{Cell lines}

HSC-3 (human tongue squamous cell carcinoma), A549 (human lung adenocarcinoma), OUS-11 (normal human lung fibroblast-like cell), and HFL1 (human fetal lung fibroblast) cell lines were obtained from American Type Culture Collection (Manassas, VA, USA). ALL cell lines were authenticated in our lab and were used within 6 months after authentication. All the cell lines were cultured with appropriate medium (DMEM for HSC3 and A549; MEM for OUS-11; and F-12K for HFL1) supplemented with $10 \%$ fetal bovine serum (FBS) under $5 \% \mathrm{CO}_{2}$ at $37^{\circ} \mathrm{C}$.

\section{Reagents and Antibodies}

Recombinant human EGF, ZD1839 (EGFR-TKI), and anti- $\beta$-actin antibody were obtained from Sigma (St. Louis, MO, USA). AG1478 used as another EGFR-TKI was obtained from Calbiochem (San Diego, CA, USA). For neutralizing EGFR, $\alpha$ EGFR antibody (clone LA1) was obtained from Upstate Biotechnology (Lake Placid, NY, USA). Recombinant human IL-6 and neutralizing $\alpha$ IL-6 antibody were obtained from R\&D Systems (Minneapolis,
MN, USA). Anti-pEGFR, anti-pSTAT3, anti-STAT3, antipAkt, anti-Akt, anti-pMAPK, and anti-MAPK antibodies were purchased from Cell Signaling Technology (Danvers, MA, USA). Anti-EGFR, anti-collagen 1A1 (COL1A1), and anti- $\alpha$-actin antibodies were purchased from Santa Cruz Biotechnology (Santa Cruz, CA, USA).

\section{Cell proliferation assay}

Cells were seeded onto 96-well plate at a density of $1 \times 10^{3}$ cells/well. Two days after seeding, the cells were treated with EGFR-TKI and incubated in $5 \% \mathrm{CO}_{2}$ at $37 \mathrm{C}$ for 24-96 hrs. Cell growth was then measured, using TetraColor ONE (Seikagakukogyo, Tokyo, Japan), according to manufacturer's procedures. Absorbance was measured at $530 \mathrm{~nm}$ and $630 \mathrm{~nm}$ as references.

\section{Western blotting}

HSC-3 and A549 cells were seeded onto 6-well plate at a density of $1 \times 10^{5}$ cells/well. Two days after seeding, the cells were pretreated with EGFR-TKI or $\alpha$ EGFR antibody for $30 \mathrm{~min}$ and then treated with EGF. OUS-11 and HFL1 cells were seeded onto 6-well plate at a density of $1 \times 10^{5}$ cells/well. At a day after seeding, the cells were pretreated with neutralizing $\alpha$ IL- 6 antibody for 30 min and then treated with IL-6. These cells were washed twice with ice-cold phosphate-buffered saline (PBS) and lysed in ice-cold RIPA buffer. After boiling cell lysate (10 $\mu \mathrm{g})$ with gel loading buffer for $5 \mathrm{~min}$, the samples were subjected to SDS-PAGE on $7.5 \%$ gel and transferred to

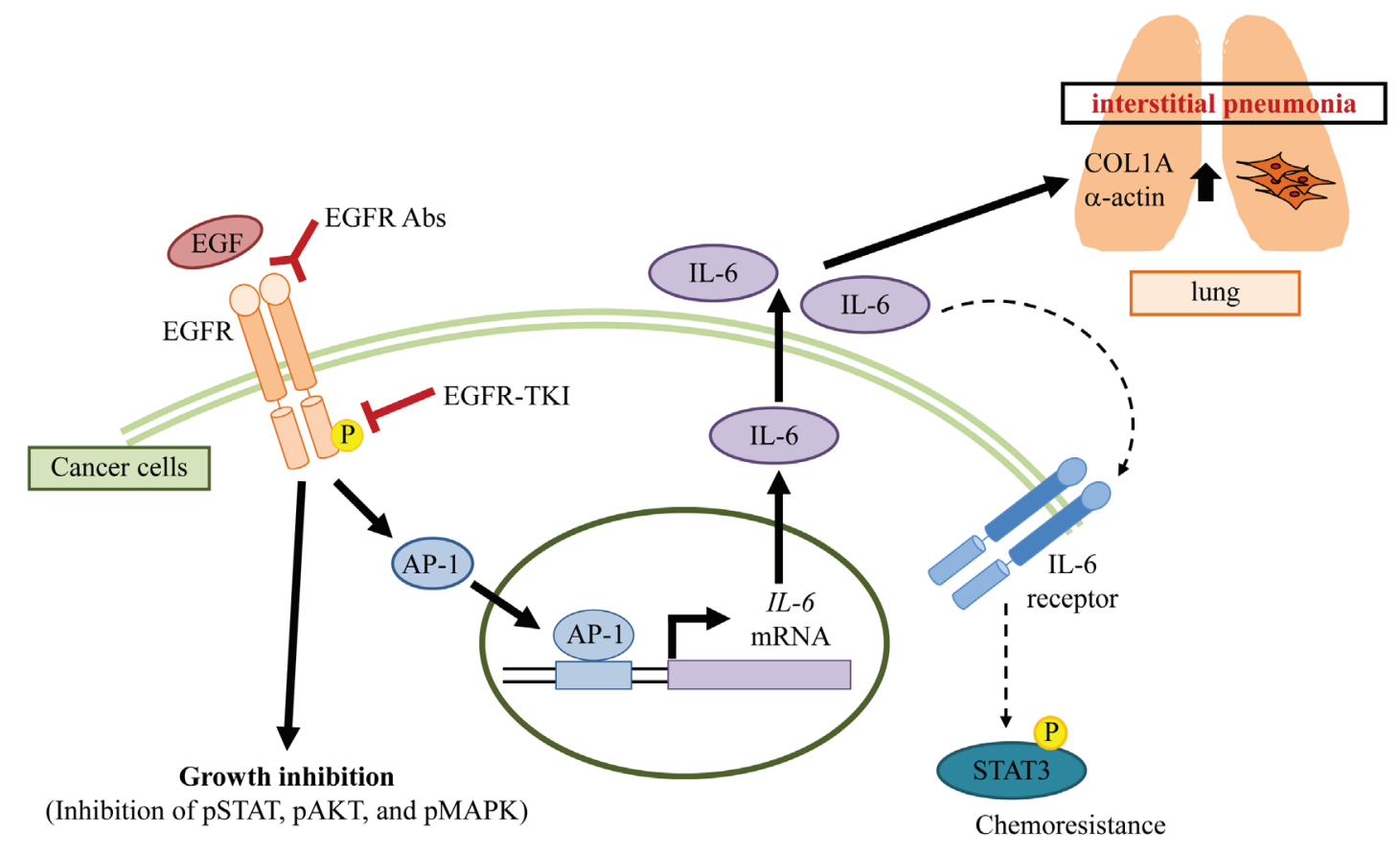

Figure 6: A potential mechanism of interstitial pneumonia induced by EGFR blocking. 
Immobilon-P (Millipore, Billerica, MA). After blocking the membrane with blocking reagent (NOF, Tokyo, Japan), western blotting was done using the antibody of interest, and the products were detected with Immobilon Western Chemiluminescent HRP substrate (Millipore).

\section{Cytokine Antibody array}

Cytokines in CM were detected, using Human Cytokine Array V (Ray Biotech, Norcross, GA, USA), according to the manufacturer's instructions. HSC-3 or A549 $\left(1 \times 10^{5}\right.$ cells seeded in 6-well plate and incubated for $48 \mathrm{hrs}$ ) were treated with EGFR-TKI or $\alpha E G F R$ antibody. After $24 \mathrm{hrs}$ incubation, medium was collected as $\mathrm{CM}$ and $\mathrm{CM}$ was used for cytokine membrane assay. Detected signal density was measured by ScionImage Software.

\section{Quantification of IL-6 and COL1A1 mRNA by qPCR}

HSC-3 or OUS-11 cells were seeded onto 6-well plate at a density of $1 \times 10^{5}$ cells/well. One (for HSC3 ) or two (for OUS-11) days after seeding, the cells were treated with EGFR-TKI or $\alpha$ EGFR antibody for 24 hrs, treated with CM for $72 \mathrm{hrs}$, or pretreated with $\alpha \mathrm{IL}-$ 6 antibody for $30 \mathrm{~min}$ and then treated with IL-6 for 72 hrs. After each treatment, total RNA was extracted using ISOGEN (Nippon Gene, Toyama, Japan) according to the manufacturer's instructions. cDNA was synthesized using High Capacity cDNA Reverse Transcription Kit (Life Technologies, Grand Island, NY). qPCR was assayed using TaqMan Fast Advanced Mastermix and TaqMan according to the manufacturer's protocol (Life Technologies). GAPDH was used as an internal control.

\section{Quantification of IL-6 secretion by ELISA}

HSC-3 cells $\left(1 \times 10^{5}\right.$ cells/well $)$ were seeded onto 6-well plates. Two days after seeding, the cells were treated with EGFR-TKI or $\alpha$ EGFR antibody. After incubation, the culture supernatants were collected and the number of cells was counted. The levels of IL- 6 were analyzed by human IL-6 ELISA kit II according to the manufacturer's protocol (BD Biosciences) and adjusted by the total number of cells.

\section{OUS-11 and HFL1 co-cultured with HSC-3.}

OUS-11 and HFL1 cells were seeded onto 6-well plate at a density of $1 \times 10^{5}$ cells/well. Then, HSC-3 cells were seeded onto cell culture insert at a density of $1 \times 10^{4}$ cells. Two days after seeding, cell culture insert was set on wells of the 6-well plates, and cultured with EGFR-
TKI or $\alpha$ EGFR antibody for 7 days in $5 \% \mathrm{CO}_{2}$ at $37^{\circ} \mathrm{C}$. Thereafter, the cells were washed twice with ice-cold PBS and lysed in ice-cold RIPA buffer. Then, COL1A1 and $\alpha$-actin expression was assayed by western blot.

\section{Luciferase assay}

pGL4-IL-6 promoter luciferase vector was obtained as described in a previously report [30]. AP-1 luciferase vector was purchased from Clontech (Palo Alto, CA). phRL-SV40 (Promega, Madison, WI) was used as the internal control. HSC-3 cells were seeded onto 24-well plate at a density of $5 \times 10^{4}$ cells. After the vectors were transfected using Transfast reagents (Promega), the cells were treated with drug and incubated for $48 \mathrm{hrs}$. Then, the cells were lysed and assayed using the dual-luciferase reporter assay system (Promega) and a luminometer, TD20/20 (Turner Design, Sunnyvale, CA).

\section{ACKNOWLEDGEMENTS}

The authors are grateful to Dr. Mamoru Tsukuda at Yokohama City University Graduate School of Medicine for kind support. The authors also thank Ms. Miyuki Ishii for a technical assistance.

\section{REFERENCES}

1. Mojtahedi H, Essapen S. Epidermal growth factor receptor inhibitors in cancer treatment: advances, challenges and opportunities. Anticancer Drugs. 2009;20:851-855.

2. Lynch TJ, Bell DW, Sordella R, Gurubhagavatula S, Okimoto RA, Brannigan BW, Harris PL, Haserlat SM, Supko JG, Haluska FG, Louis DN, Christiani DC, Settleman J, Haber DA. Activating mutations in the epidermal growth factor receptor underlying responsiveness of non-smallcell lung cancer to gefitinib. The New England Journal of Medicine. 2004;350:2129-2139.

3. Mitsudomi T, Yatabe Y. Mutations of the epidermal growth factor receptor gene and related genes as determinants of epidermal growth factor receptor tyrosine kinase inhibitors sensitivity in lung cancer. Cancer Science. 2007;98:18171824.

4. Morita S, Okamoto I, Kobayashi K, Yamazaki K, Asahina H, Inoue A, Hagiwara K, Sunaga N, Yanagitani N, Hida T, Yoshida K, Hirashima T, Yasumoto K, Sugio K, Mitsudomi T, Fukuoka M, et al. Combined survival analysis of prospective clinical trials of gefitinib for non-small cell lung cancer with EGFR mutations. Clinical Cancer Research. 2009;15:4493-4498.

5. Ludovini V, Bianconi F, Pistola L, Pistola V, Chiari R, Colella R, Bellezza G, Tofanetti FR, Siggillino A, Baldelli E, Flacco A, Giuffrida D, Sidoni A, Crinò L. Optimization of patient selection for EGFR-TKIs in advanced non-small 
cell lung cancer by combined analysis of KRAS, PIK3CA, MET, and non-sensitizing EGFR mutations. Cancer Chemotherapy and Pharmacology. 2012;69:1289-1299.

6. Rabinowits G, Haddad RI. Overcoming resistance to EGFR inhibitor in head and neck cancer: A review of the literature. Oral Oncology. 2012;48:1085-1089.

7. Inoue A, Saijo Y, Maemondo M, Gomi K, Tokue Y, Kimura Y, Ebina M, Kikuchi T, Moriya T, Nukiwa T. Severe acute interstitial pneumonia and gefitinib. Lancet 2003;361:137139.

8. Usui K, Ushijima T, Tanaka Y, Tanai C, Noda H, Abe N, Horiuchi $\mathrm{H}$, Ishihara $\mathrm{T}$. The frequency of epidermal growth factor receptor mutation of nonsmall cell lung cancer according to the underlying pulmonary diseases. Pulmonary Medicine. 2011;2011:290132.

9. Takano T, Ohe Y, Kusumoto M, Tateishi U, Yamamoto S, Nokihara H, Yamamoto N, Sekine I, Kunitoh H, Tamura T, Kodama T, Saijo N. Risk factors for interstitial lung disease and predictive factors for tumor response in patients with advanced non-small cell lung cancer treated with gefitinib. Lung Cancer. 2004;45:93-104.

10. Kudoh S, Kato H, Nishiwaki Y, Fukuoka M, Nakata K, Ichinose Y, Tsuboi M, Yokota S, Nakagawa K, Suga M, Japan Thoracic Radiology Group, Jiang H, Itoh Y, Armour A, Watkins C, Higenbottam T, et al. Interstitial lung disease in Japanese patients with lung cancer: a cohort and nested case-control study. American Journal of Respiratory and Critical Care Medicine. 2008;177:1348-1357.

11. Ando M, Okamoto I, Yamamoto N, Takeda K, Tamura K, Seto T, Ariyoshi Y, Fukuoka M. Predictive factors for interstitial lung disease, antitumor response, and survival in non-small-cell lung cancer patients treated with gefitinib. Journal of Clinical Oncology. 2006;24:2549-2556.

12. Okamoto M, Kato S, Oizumi K, Kinoshita M, Inoue Y, Hoshino K, Akira S, McKenzie AN, Young HA, Hoshino T. Interleukin 18 (IL-18) in synergy with IL-2 induces lethal lung injury in mice: a potential role for cytokines, chemokines, and natural killer cells in the pathogenesis of interstitial pneumonia. Blood. 2002;99:1289-1298.

13. Kim SM., Kwon OJ., Hong YK, Kim JH, Solca F, Ha SJ, Soo RA, Christensen JG, Lee JH, Cho BC. Activation of IL-6R/JAK1/STAT3 signaling induces de novo resistance to irreversible EGFR inhibitors in non-small cell lung cancer with T790M resistance mutation. Molecular Cancer Therapeutics. 2012;11:2254-2264.

14. Schafer ZT, Brugge JS. IL-6 involvement in epithelial cancers. The Journal of Clinical Investigation. 2007; 117:3660-3663.

15. Guo Y, Xu F, Lu TJ, Duan Z, Zhang Z. Interleukin-6 signaling pathway in targeted therapy for cancer. Cancer Treatment Reviews. 2012;38:904-910.

16. Sen M, Joyce S, Panahandeh M, Li C, Thomas SM, Maxwell J, Wang L, Gooding WE, Johnson DE, Grandis JR. Targeting Stat3 abrogates EGFR inhibitor resistance in cancer. Clinical Cancer Research. 2012;18:4986-4996.

17. Knight DA, Ernst M, Anderson GP, Moodley YP, Mutsaers SE. The role of gp130/IL-6 cytokines in the development of pulmonary fibrosis: critical determinants of disease susceptibility and progression? Pharmacology \& Therapeutics. 2003;99:327-338.

18. Moodley YP, Misso NL, Scaffidi AK, Fogel-Petrovic M, McAnulty RJ, Laurent GJ, Thompson PJ, Knight DA. Inverse effects of interleukin-6 on apoptosis of fibroblasts from pulmonary fibrosis and normal lungs. American journal of respiratory cell and molecular biology. 2003;29:490-498.

19. Chen Y, Rubin P, Williams J, Hernady E, Smudzin T, Okunieff P. Circulating IL-6 as a predictor of radiation pneumonitis. International Journal of Radiation Oncology, Biology, Physics. 2001;49:641-648.

20. Yoshida M, Sakuma J, Hayashi S, Abe K, Saito I, Harada S, Sakatani M, Yamamoto S, Matsumoto N, Kaneda Y, Kishimoto T. A histologically distinctive interstitial pneumonia induced by over expression of the interleukin 6 , transforming growth factor beta 1 , or platelet-derived growth factor B gene. Proceedings of the National Academy of Science of the United States of America. 1995;92:95709574.

21. Aggarwal BB, Kunnumakkara AB, Harikumar KB, Gupta SR, Tharakan ST, Koca C, Dey S, Sung B. Signal transducer and activator of transcription-3, inflammation, and cancer: how intimate is the relationship?. Annals of the New York Academy of Sciences. 2009;1171:59-76.

22. Zerbini LF, Wang Y, Cho JY, Libermann TA. Constitutive activation of nuclear factor $\kappa \mathrm{B}$ p50/p65 and Fra-1 and JunD is essential for deregulated interleukin 6 expression in prostate cancer. Cancer Research. 2003;63:2206-2215.

23. Takada Y, Gresh L, Bozec A, Ikeda E, Kamiya K, Watanabe M, Kobayashi K, Asano K, Toyama Y, Wagner EF, Matsuo $\mathrm{K}$. Interstitial lung disease induced by gefinitib and tolllike receptor ligands is mediated by Fra-1. Oncogene. 2011;30:3821-3832.

24. Slinger E, Maussang D, Schreiber A, Siderius M, Rahbar A, Fraile-Ramos A, Lira SA, Söderberg-Nauclér C, Smit MJ. HCMV-Encoded chemokine receptor US28 mediates proliferative signaling through the IL-6-STAT3 axis. Science Signaling. 2010;3:ra58.

25. Yao Z, Fenoglio S, Gao DC, Camiolo M, Stiles B, Lindsted T, Schlederer M, Johns C, Altorki N, Mittal V, Kenner L, Sordella R. TGF- $\beta$ IL- 6 axis mediates selective and adaptive mechanisms of resistance to molecular targeted therapy in lung cancer. Proceedings of the National Academy of Science of the United States of America. 2010;107:1553515540 .

26. Namba T, Tanaka KI, Hoshino T, Azuma A, Mizushima T. Suppression of expression of heat shock protein 70 by gefitinib and Its contribution to pulmonary fibrosis. PLoS One. 2011;6:e27296. 
27. MacKinnon AC, Gibbons MA, Farnworth SL, Leffler H, Nilsson UJ, Delaine T, Simpson AJ, Forbes SJ, Hirani N, Gauldie J, Sethi T. Regulation of transforming growth factor- $\beta 1$-driven lung fibrosis by galectin-3. American journal of respiratory and critical care medicine. 2012;185:537-546.

28. Ma F, Li Y, Jia L, Han Y, Cheng J, Li H, Qi Y, Du J. Macrophage-stimulated cardiac fibroblast production of IL- 6 is essential for TGF $\beta /$ Smad activation and cardiac fibrosis induced by angiotensin II. PLoS One. 2012; 7:e35144.

29. Mathur S, Walley KR, Wang Y, Indrambarya T, Boyd JH. Extracellular heat shock protein 70 induces cardiomyocyte inflammation and contractile dysfunction via TLR2. Circulation Journal. 2011;75:2445-2452.

30. Ishiguro H, Akimoto K, Nagashima Y, Kojima Y, Sasaki T, Ishiguro-Imagawa Y, Nakaigawa N, Ohno S, Kubota $\mathrm{Y}$, Uemura H. aPKC $\lambda / \mathrm{l}$ promotes growth of prostate cancer cells in an autocrine manner through transcriptional activation of interleukin-6. Proceedings of the National Academy of Science of the United States of America. 2009;106:16369-16374. 